\title{
EXPERIMENTAÇÃO CONTEXTUALIZADA SOBRE EQUILÍBRIO QUÍMICO PARA TURMA DE ENSINO MÉDIO
}

\section{CONTEXTUALIZED EXPERIMENTATION ON CHEMICAL EQUILIBRIUM FOR HIGH SCHOOL CLASS}

\author{
Autores: \\ ${ }^{1}$ Dr. ${ }^{a}$ Alessandra Marcone Tavares Alves de Figueirêdo \\ Doutora em Química e Professora da Licencatura em Química, IFPB - campus João Pessoa - Paraíba, \\ Brasil. \\ ${ }^{2}$ Carlos Alberto da Silva Júnior \\ Graduando em Licenciatura em Química, IFPB - campus João Pessoa - Paraíba, Brasil. \\ ${ }^{3}$ Daniel Gabriel da Silva \\ Graduando em Licenciatura em Química, IFPB - campus João Pessoa - Paraíba, Brasil. \\ ${ }^{4}$ Márcio Jean Fernandes Tavares \\ Graduando em Licenciatura em Química, IFPB - campus João Pessoa - Paraíba, Brasil. \\ ${ }^{1}$ Dr. Jaime Patricio Leiva Núñez \\ Doctor en Didácticas de las Ciencias de la educación, Profesor de Biología y Ciencias, Licenciado en \\ Educación, Diplomado en Estadística y Computación Educativa, Coordinador Sello Tic de la \\ Universidad de Playa Ancha, Departamento de Matemática y Estadística, Facultad de Ciencias, UPLA \\ - Valparaíso, Chile.
}

\section{Orientadora:}

Dr. ${ }^{a}$ Alessandra Marcone Tavares Alves de Figueirêdo

Contato do autor principal:

alessandratavaresfigueiredo@ifpb.edu.br

Av. $1^{\circ}$ de Maio, 720, Jaguaribe, João Pessoa, PB - Brasil - CEP: 58.015-430. 


\title{
EXPERIMENTAÇÃO CONTEXTUALIZADA SOBRE EQUILÍBRIO QUÍMICO PARA TURMA DE ENSINO MÉDIO
}

\section{CONTEXTUALIZED EXPERIMENTATION ON CHEMICAL EQUILIBRIUM FOR HIGH SCHOOL CLASS}

\author{
${ }^{1}$ Alessandra Marcone Tavares Alves de Figueirêdo; ${ }^{2}$ Carlos Alberto da Silva Júnior; ${ }^{3}$ Daniel Gabriel \\ da Silva; ${ }^{4}$ Márcio Jean Fernandes Tavares; ${ }^{5}$ Jaime Patricio Leiva Núñez
}

\begin{abstract}
Resumo: No Brasil, o Governo Federal, em 2016, lançou uma medida provisória (MP) sobre a reforma do Ensino Médio, visando diminuir os altos índices de evasão nas escolas. O problema dessa MP é focarse muito em mudanças temerárias e superficiais, enquanto que as maiores dificuldades se concentram nas metodologias obsoletas utilizadas em sala de aula, na falta de formação continuada dos professores e, ainda, na insuficiência de profissionais na área, esses são pontos cruciais onde as verdadeiras reformas políticas deveriam acontecer. Neste último, sobre a escassez de docentes, a problemática é mais acentuada na área das Ciências Exatas, como na disciplina Química, logo, faz-se necessária alguma ação para incentivar os discentes a seguirem a carreira docente. Neste sentido, surgiu o Programa Internacional - PDVL que tem como objetivo desenvolver ações no intuito de despertar o interesse dos estudantes pela Licenciatura. Este programa tem caráter de ensino, pesquisa e extensão e participam dele alguns licenciandos em Química do Instituto Federal da Paraíba - IFPB, campus João Pessoa que estão à frente deste trabalho. Para tanto, é de suma importância desenvolver atividades que despertem a motivação e o interesse por essa Ciência. Com isso, o objetivo dessa pesquisa foi desenvolver e aplicar experimentos, especificamente com o conteúdo sobre o Princípio de Le Chatelier, na tríade, Ciência, Tecnologia e Sociedade (CTS), no intuito de facilitar o processo de ensino-aprendizagem da disciplina Química. A metodologia do trabalho foi desenvolvida sob uma perspectiva quantiqualitativa e participante, integrada à realidade dos discentes. Trabalhou-se com 20 (vinte) alunos de uma turma do $3^{\circ}$ ano do Ensino Médio, da Escola Estadual de Ensino Fundamental e Médio José Baptista de Mello, localizada no bairro de Mangabeira, em João Pessoa, Paraíba-Brasil. Os resultados obtidos mostraram que houve um impacto positivo no aprendizado dos discentes, por meio de uma avaliação processual, quantitativa e qualitativa.
\end{abstract}

Palavras-chave: Ciência-Tecnologia-Sociedade - CTS, Despertar para Docência, Experimentação, Ensino de Química, Princípio de Le Chatelier.

Abstract: In Brazil, the Federal Government, in 2016, launched a provisional measure (MP) on the reform of High School, aiming to reduce the high rates of school dropout. The problem of this MP is to focus a lot on reckless and superficial changes, while the greatest difficulties are concentrated in the obsolete methodologies used in the classroom, in the lack of continuous training of the teachers and, also, in the insufficiency of professionals in the area. These are crucial points where real political reforms should take place. About the shortage of teachers, the problem is more pronounced in the area of Exact Sciences, as for example in the discipline Chemistry. Therefore, some action is necessary to encourage the students to follow the teaching career. In this sense, the International Program - PDVL was created. One of the many objectives in this program is to develop actions in order to arouse students' interest in the Degree. The PDVL has the character of teaching, research and extension, which some of the chemistry graduates of the Federal Institute of Paraíba - IFPB, João Pessoa campus, are at the forefront of this work. It is extremely important to develop activities that arouse motivation and interest in this Science. The aim of this research was to develop and apply experiments, specifically with the content on the Le Chatelier's Principle, in the triad, Science, Technology and Society (STS), in order to facilitate the learning process of the Chemical discipline. The methodology of this work was developed from a qualitative, quantitative and participant perspective, integrated to the reality of the students. We worked with 20 (twenty) students of a class of the 3rd year of High School, State School of Primary and Secondary Education José Baptista de Mello, located in the neighborhood of Mangabeira, in the city of João Pessoa, Paraíba - Brazil. The results showed that there was a positive impact on student learning through a quantitative and qualitative process evaluation.

Keywords: Science-Technology-Society - STS, Awakening for Teaching, Experimentation, Teaching Chemistry, Le Chatelier's Principle. 


\section{INTRODUÇÃO}

Nas últimas décadas, com o avanço da globalização e da automação diversos países têm repensado seu modelo de educação frente a um mundo cada vez mais competitivo e de realidades econômicas diferentes. No Brasil, nação sede dos últimos Jogos Olímpicos, o Governo Federal, em 2016, lançou uma medida provisória (MP) sobre a reforma do Ensino Médio. Dentre as principais mudanças, propõe-se a flexibilização da grade curricular e o aumento do número de horas aulas. De acordo com a Agência Brasil (2016): “As mudanças pretendem favorecer, também, a aplicação dos conhecimentos em diversas áreas - inclusive no dia a dia dos discentes e na realidade do Brasil e do mundo". Tais mudanças, embora causem grandes repercussões, não são inéditas.

Desde o século passado, a Educação no Brasil vem sendo modificada de acordo com as necessidades do público alvo, mas ainda versa um quadro caótico em relação às abordagens de ensino utilizadas pelos docentes, em especial na rede pública. As mudanças propostas em 2016 afetam o conteúdo e o formato das aulas, buscando, teoricamente, diminuir os altos índices de evasão, tornando o Ensino Médio mais “atrativo". Segundo as estatísticas da educação básica do Instituto Nacional de Estudos e Pesquisas Educacionais Anísio Teixeira (INEP), em 2015 foram efetuadas 7,02 milhões de matrículas na rede pública e 1,05 milhão na rede privada no Ensino Médio (INEP, 2015). Logo, existe um contingente maior de matrículas de estudantes no setor público do que no privado.

Dentro desse contexto, indagam-se uma série de questionamentos como: As mudanças propostas pelo Governo Federal seriam suficientes para garantir uma real "motivação" e, consequentemente, uma diminuição da evasão? Não se deveria focar na reformulação das metodologias de ensino utilizadas em sala de aula, bem como na formação continuada dos professores? E quanto ao Ensino de Química, ele tem sido trabalhado de modo significativo no setor educacional público? Diante dessas premissas, infere-se que precisa sim haver uma mudança do Ensino Médio, mas a forma como está sendo feita é impensada e insuficiente. Logo, é imprescindível, uma verdadeira e democrática mudança nos métodos de ensino empregados em sala de aula, principalmente no Ensino de Química, pois as metodologias utilizadas pelos docentes e a infraestrutura das escolas, em geral, são ineficientes, além de não haver uma capacitação e valorização dos professores.

Essas problemáticas afetam, sobretudo, o Ensino de Química, este é considerado tedioso por muitos estudantes, pois, para muitos ele não proporciona uma compreensão significativa, 
uma vez que a metodologia utilizada em muitas instituições perpetua a ideia de "modelobancário", destacado por Freire (2014), limitando o desenvolvimento cognitivo dos educandos, considerando-os como meros ouvintes sem participação ativa na aprendizagem.

Segundo os Parâmetros Curriculares Nacionais + (PCN+), ter acesso aos conceitos e conhecimentos químicos “[...] deve possibilitar ao aluno a compreensão tanto dos processos químicos em si quanto da construção de um conhecimento científico em estreita relação com as aplicações tecnológicas e suas implicações ambientais, sociais, políticas e econômicas" (BRASIL, 2002, p. 87). Sendo assim, o Ensino de Química tornou-se um desafio que precisa ser superado pelos docentes da referida Ciência. O uso de metodologias estáticas, ao decorrer dos anos, gera uma aprendizagem frágil e versada em informações superficiais. As medidas provisórias do Governo Federal deveriam mirar nesse aspecto quanto à reforma do Ensino Médio.

Nesse sentido, no intuito de mudar o método de ensino atualmente utilizado nas escolas e de despertar o interesse dos estudantes pela Química é indispensável fazer uso de metodologias diversificadas e atrativas, uma delas é a experimentação contextualizada, tendo em vista que esta Ciência é puramente experimental. Todavia, devem-se priorizar articulações efetivas entre teoria e prática, para dar significado aos conceitos.

Diante do exposto, a pesquisa tem como objetivo desenvolver ações planejadas, com uma abordagem de Ciência, Tecnologia e Sociedade, que despertem o interesse dos discentes para com essa Ciência, de uma forma que o alunado consiga perceber a Química em diversas situações do cotidiano, na intenção de facilitar a construção do conhecimento significativo.

\section{FUNDAMENTAÇÃO TEÓRICA}

\section{Um Relance Sobre O Sistema Educacional Brasileiro}

A história do sistema educacional brasileiro é um grande desafio, não objetivado nesse trabalho. No entanto, faz-se necessário apenas um relance no passado histórico da Lei de Diretrizes e Bases da Educação Nacional - LBD, que regulamenta a educação no Brasil, para que o entendimento dos desafios encontrados possa ser melhor elucidado. Desde a década de 70, diversas mudanças têm sido discutidas. As mobilizações sociais e outros fatores da época levaram a atual Constituição de 1988, que além de assegurar direitos à educação básica, também estabelece princípios do ensino. Foi então, nesse contexto, que o maior referencial político para essa discussão surgiu, a saber, a Lei de Diretrizes e Bases da Educação Nacional. Historicamente a: 
Primeira LDB foi a Lei $\mathrm{n}^{\circ} 4.024$, de 1961, que regulamentava a Constituição democrática de 1946. A segunda LDB, chamada Lei da Reforma do Ensino de $1^{\circ}$ e $2^{\circ}$ graus, foi a Lei $\mathrm{n}^{\circ}$ 5.692, de 1971, editada no decurso da ditadura militar, sob a Constituição de 1967. A terceira, atualmente em vigor, é a Lei no 9.394, de 20 de dezembro de 1996. (BRASIL, 2012, p. 37)

Pela LDB, a educação escolar estrutura-se em dois grandes níveis: básica e superior. $\mathrm{Na}$ educação básica, segundo o artigo $4^{\circ}$, o Estado garante a "educação básica obrigatória e gratuita dos 4 (quatro) aos 17 (dezessete) anos de idade” (BRASIL, 1996). Desse modo, é garantido por lei o acesso ao ensino fundamental e médio a todos os cidadãos.

Ao longo desses anos, o Governo Federal tem dado acesso à educação para todos os brasileiros, mas, infelizmente, não tem garantido a permanência. A mais recente medida provisória sobre a reforma do Ensino Médio visa justamente atenuar a evasão e tornar esse ensino mais atraente. Tais medidas devem-se também ao não atingimento das metas estabelecidas pelo Índice de Desenvolvimento da Educação Básica (IDEB).

Essas problemáticas são mais exacerbadas nas disciplinas pertencentes à área das Ciências Exatas, particularmente na Química, como descrito nos Parâmetros Curriculares Nacionais do Ensino Médio (PCNEM): "Na escola, de modo geral, o indivíduo interage com um conhecimento essencialmente acadêmico, principalmente através da transmissão de informações, supondo que o estudante, memorizando-as passivamente, adquira o conhecimento acumulado" (BRASIL, 1999, p. 64).

Diante disso, para evitar que o estudante seja apenas um receptor e o docente o transmissor de conteúdos, devem-se mudar as atuais metodologias de ensino praticadas por grande parte dos professores. Como afirma Souza e Justi (2005):

\begin{abstract}
os educadores devem buscar diferentes estratégias de ensino em suas áreas de atuação disciplinar, visando ampliar a magnitude de tal ensino, o que conduziria ao rompimento do paradigma tradicional que rege o ensino de um modo geral. As propostas mais recentes de ensino de química têm como um dos pressupostos a necessidade do envolvimento ativo dos alunos nas aulas, em um processo interativo professor/aluno, em que os horizontes conceituais dos alunos sejam contemplados (SOUZA; JUSTI, 2005).
\end{abstract}

Dentro desse contexto, deve haver uma contextualização nas aulas, isto é, deve-se relacioná-las com a vivência dos estudantes. Outro ponto de fundamental importância, para o fortalecimento do aprendizado em Química, é usar uma metodologia de ensino diversificada, como por exemplo, a experimentação.

Segundo Souza “o uso da experimentação é uma forma de contextualizar os conteúdos de Ciências [...] relacionando-os com situações do cotidiano dos alunos, situações essas que exigem a abordagem interdisciplinar e até transdisciplinar" (2013, p. 29). Como visto, aulas experimentais enriquecem o conhecimento. Elas devem aguçar o interesse e despertar o 
raciocínio crítico dos alunos.

Para a realização prática de um experimento, é necessário considerar variáveis como: a infraestrutura escolar (observar se a instituição escolar possui um laboratório apropriado ou algum local passivo de serem realizados experimentos), como afirma Nardi (1998): "Podemos citar, por exemplo, a falta de laboratórios e equipamentos no colégio, [...] que impede uma preparação adequada de aulas práticas...”, sendo assim, muitas vezes, se faz necessária uma "improvisação" de um laboratório temporário (preparo da sala de aula ou outro espaço previamente) por parte do docente, além do material e os reagentes cabíveis ao experimento e, primordialmente, a seleção do experimento. Tais experimentos realizados necessitam ser do cotidiano dos discentes e perfeitamente visíveis a olho nu, para que causem um grande impacto visual, despertando curiosidade até mesmo nos estudantes mais desconexos ao conteúdo e a matéria. É de grande valia ao experimento não apresentar grande perigo (sejam eles de intoxicação, explosão e ou forte liberação de gás nocivo), sendo preferíveis experimentos "limpos" (sem risco aos alunos e ao professor), sendo primordial a explicação teórica de uma forma completa, mas de modo simples na qual a mesma possa ser indagada ou questionada pelos próprios estudantes.

Tais atribuições são importantes para ser possível unificar teoria e prática. Todas as observações (explicações) realizadas ao experimento devem estar conectadas a conhecimentos previamente obtidos pelos discentes (sejam eles recebidos em aulas anteriores ou na aula de aplicação do experimento) e explicadas de maneira objetiva.

Diante disso, a inclusão de uma metodologia de ensino diferenciada entrará em acordo com a visão de ensino de Piaget (1975), na qual o indivíduo passa por dois importantes processos: associação e acomodação do conhecimento, de forma que o experimento irá se associar com o conteúdo teórico ministrado e tal associação gerará uma acomodação, ou seja, o leque de conhecimento será ampliado, interligando assim o experimento ao conteúdo ministrado, como por exemplo: o discente observa o experimento que mostra o aumento da velocidade de uma reação, o alusivo experimento está conectado ao assunto de cinética química, mais precisamente aos catalisadores, logo, o estudante notará semelhanças entre o experimento e o assunto teórico e no momento que for citado o conteúdo de cinética química, o discente lembrar-se-á do experimento e do conteúdo referente ao mesmo.

Portanto, faz-se necessário uma ampla discussão e efetivação de ações didáticopedagógicas, como o uso da experimentação, que possibilitem a permanência e o êxito dos alunos de Ensino Médio na escola, assim como desperte o interesse deles pela disciplina Química. 
Após essa caracterização do setor educacional brasileiro, nos próximos tópicos, serão discutidos os principais desafios no Ensino de Química, considerado por muitos discentes como sendo abstrato e subjetivo. Por fim, será aplicada uma práxis, especificamente no estudo do Princípio de Le Chatelier.

\title{
O Desafio Do Ensino De Química No Brasil
}

Particularmente no ensino de Química do Brasil, nota-se que os alunos na maioria das vezes não conseguem assimilar o conteúdo abordado em sala de aula com a sua própria vivência, sendo assim, a abordagem adotada pelo professor está caracterizada como descontextualizada, causando uma grande dificuldade no aprendizado do discente, tornando o conteúdo desta disciplina uma "pedra de tropeço" no desenvolvimento intelectual do aluno. Segundo Freire (2005), a contextualização é a unificação do conteúdo demonstrado em sala de aula com a vivência do aluno, não ficando restrita a área de atuação da matéria ensinada, mas aplicando um conteúdo interdisciplinar. Como afirma o Guia de Livros Didáticos PNLD 2017:

\begin{abstract}
Na coleção, são várias as situações nas quais o conhecimento químico é vinculado ao cotidiano do aluno; contudo, para permitir uma construção mais crítica da cidadania, há a necessidade de problematizações mais profundas dos temas sociais. A manifestação de que o diálogo com outras áreas do conhecimento é importante e todo conhecimento faz uso dele está explicitada de forma mais clara na seção, Informe-se sobre a Química, que aparece apenas no final de cada capítulo, o que torna tal diálogo incipiente. (BRASIL, 2017).
\end{abstract}

Sendo assim, a contextualização é um dos vastos recursos metodológicos existentes, que pode ser utilizada com o intuito de despertar o interesse do alunado, pois não basta ministrar o conteúdo científico e, em seguida, mostrar uma aplicabilidade no cotidiano, mas sim, partir de uma situação social, econômica, ética ou política problematizadora que incentive a curiosidade do alunado em tentar solucionar o problema, podendo assim, inserir o conhecimento científico necessário para explicá-lo. Tais afirmações acabam por levar ao contexto interdisciplinar. A interdisciplinaridade é o processo de ligação entre disciplinas que permite levar luz a camadas mais profundas e obscuras da realidade que se quer estudar, causando um entendimento mútuo do conteúdo estudado, sendo assim, um processo que precisa ser vivido e exercido (CATARINA, 2008).

Um grande empecilho que está enraizado no ensino de Química é a dificuldade de aplicação de experimentos devido ao fato de muitas escolas públicas não possuírem a estrutura adequada para implementação de um laboratório, sendo assim, os professores acabam por se valerem apenas de recursos expositivos como, quadro e lápis e, quando se tem, utilizam o projetor multimídia, conforme Barbosa et. al.: 


\begin{abstract}
Muitos professores dizem querer realizar mais experimentação com seus alunos, já que atividades desse padrão são motivadoras. Porém, a prévia preparação que os experimentos sugeridos exigem e a demanda de materiais inviabilizam aplicar atividades experimentais. É certo que os docentes podem buscar alternativas, todavia, seria desperdício não utilizar o Caderno do Aluno. Surge, portanto, a necessidade de adaptação de alguns experimentos à realidade de nossa rotina. (2013, p. 29)
\end{abstract}

Devido a tais fatos apresentados os professores veem-se impossibilitados de apresentarem aos seus alunos uma demonstração prática do conteúdo ensinado em sala de aula, sendo assim, 'forçados' a se munirem de uma metodologia "básica" que não pode demonstrar o potencial máximo da Química, tornando assim, por inúmeras vezes, o conteúdo dessa disciplina incompreensível para alunos do Ensino Médio. Para se desviarem de problemas como esses, alguns professores fazem uso das Tecnologias da Informação e Comunicação (TICs), que para Belloni (2005), é a fusão de três vertentes tecnológicas: a informática, mídias eletrônicas e telecomunicação. Considerando que, na última década, a presença de tais vertentes no contexto socioeducacional cresceu e se tornou muito importante no processo de ensino e aprendizagem.

\title{
METODOLOGIA
}

A presente pesquisa foi realizada com 20 (vinte) alunos de uma turma do $3^{\circ}$ ano do Ensino Médio, da Escola Estadual de Ensino Fundamental e Médio José Baptista de Mello, localizada no bairro de Mangabeira, na cidade de João Pessoa, Paraíba-Brasil. Foram necessários quatro encontros, totalizando 08 (oito) aulas de 30 minutos cada, para o desenvolvimento da pesquisa que ocorreu no turno da manhã.

A metodologia usada foi amparada nos pressupostos de uma pesquisa qualitativa, pois se faz necessário uma maior proximidade do pesquisador com os sujeitos da pesquisa, na inferência de aspectos qualitativos (CALEFFE; MOREIRA, 2008). Por outro lado, a metodologia também foi quantitativa, em que expõe os dados em tabulações, expressões numéricas e/ou codificações (MARCONI; LAKATOS, 2011). Além disso, a metodologia tem características de uma pesquisa participante, que segundo Severino (2008, p. 120), é definida como "aquela em que o pesquisador, para realizar a observação dos fenômenos, compartilha a vivência dos sujeitos pesquisados, participando, de forma sistemática e permanente, ao longo do tempo da pesquisa".

Inicialmente, no primeiro encontro, aplicou-se um Questionário de Sondagem (QS), com 8 (oito) questões discursivas e de múltipla escolha, no intuito de averiguar quais os 
conteúdos, já vistos em sala, os discentes menos assimilaram . Por meio deste instrumento de avaliação, pode-se verificar que o conteúdo sobre o Princípio de Le Chatelier deveria ser revisado ou ainda trabalhado de forma mais efetiva, pois o mesmo apresentou maior dificuldade de aprendizagem entre os discentes.

Em seguida, o Quadro 1 ilustra o planejamento e o desenvolvimento das atividades nos quatro encontros com a turma, em que foi abordado o princípio de Le Chatelier, assunto de Equilíbrio Químico, além dos experimentos, e os materiais e reagentes utilizados em cada encontro:

Quadro 1: Execução das atividades desenvolvidas na pesquisa. (Fonte: Própria)

\begin{tabular}{|c|c|c|}
\hline Encontro & Atividade realizada & Materiais e reagentes \\
\hline $\begin{array}{c}1^{\mathbf{o}} \\
(2 \text { aulas })\end{array}$ & Questionário de Sondagem. & \\
\hline $\begin{array}{c}2^{\mathbf{o}} \\
\text { (2 aulas) }\end{array}$ & $\begin{array}{l}\text { Aulas dialogadas e participativas } \\
\text { sobre o conteúdo de Equilíbrio } \\
\text { Químico. } \\
\text { Experimento 1: Efeito do íon } \\
\text { comum: equilíbrio de ionização da } \\
\text { amônia. }\end{array}$ & $\begin{array}{l}\text { Reagentes } \\
\text { - Solução amoniacal; } \\
\text { - Nitrato de amônio; } \\
\text { - Solução alcoólica de } \\
\text { fenolftaleína; } \\
\text { - } 150 \text { mL de água. } \\
\\
\text { Materiais } \\
\text { - Copo de } 250 \text { mL; } \\
\text { - Colher de sopa; }\end{array}$ \\
\hline $\begin{array}{c}3^{\mathbf{0}} \\
(2 \text { aulas })\end{array}$ & $\begin{array}{lccc}\text { Experimento } & \text { 2: } & \text { Efeito } & \text { da } \\
\text { concentração no equilíbrio } & \text { de } \\
\text { hidrólise do íon bicarbonato } & \end{array}$ & $\begin{array}{l}\text { Reagentes } \\
\text { - Solução alcoólica de } \\
\text { fenolftaleína; } \\
\text { - Bicarbonato de sódio; } \\
\text { - } 100 \text { mL de vinagre; } \\
\text { - } 100 \text { mL de água. } \\
\text { Materiais } \\
\text { - Erlenmeyer; } \\
\text { - Garrafa PET de } 250 \mathrm{~mL} ; \\
\text { - Mangueira flexível de látex; } \\
\text { - Pisseta. }\end{array}$ \\
\hline $\begin{array}{c}4^{\mathbf{o}} \\
\text { (2 aulas) }\end{array}$ & $\begin{array}{l}\text { Experimento 3: Efeito } \\
\text { temperatura no equilíbrio de } \\
\text { ionização da amônia. }\end{array}$ & $\begin{array}{l}\text { Reagentes } \\
\text { - Solução alcoólica de } \\
\text { fenolftaleína; } \\
\text { - } 5 \text { mL de solução de hidróxido de } \\
\text { amônio; } \\
\text { - } 100 \mathrm{~mL} \text { de água. } \\
\text { Materiais } \\
\text { - Lamparina; } \\
\text { - Fósforo; } \\
\text { - Pisseta. }\end{array}$ \\
\hline
\end{tabular}

É importante ressaltar que todos os experimentos foram realizados pelos pesquisadores, com o intuito de preservar a integridade física dos alunos. Para finalizar essa pesquisa, foi 
entregue um Questionário Final (QF), o qual continha 06 (seis) questões, entre abertas e fechadas, visando avaliar a aceitação dos discentes quanto à abordagem utilizada e o aprendizado da temática supramencionada.

\section{RESULTADOS E DISCUSSÃO}

Inicialmente, no primeiro encontro, apresentaram-se à turma os objetivos dessa pesquisa e aplicou-se um Questionário de Sondagem. Os resultados obtidos por meio desse instrumento mostraram que $70 \%$ dos estudantes não souberam responder às questões propostas, que versavam sobre o Equilíbrio Químico, com foco no Princípio de Le Chatelier, embora eles já tivessem visto e estudado esse conteúdo anteriormente. Dentro do estudo de Equilíbrio Químico, se faz necessário abordar o Princípio de Le Chatelier, entretanto, os discentes não estavam conseguindo compreender esse princípio. Sendo assim, por intermédio da trilogia CTS iniciaram-se as atividades dessa pesquisa com os discentes, abordando tal princípio (HOFSTEIN, 1998).

No segundo encontro, abordou-se com aulas dialogadas e participativas, a definição de Equilíbrio Químico, que, teoricamente, é atingido "quando as velocidades da reação direta e inversa são iguais e as concentrações dos reagentes e dos produtos não variam com o tempo.” (CHANG; GOLDSBY, 2013, p. 624). Além disso, foi discutido que existem dois tipos de Equilíbrio Químico, o homogêneo e o heterogêneo. O homogêneo existe nas reações em que envolvem reagentes e produtos no mesmo estado de agregação da matéria e o equilíbrio heterogêneo consiste em reações em que existem espécies químicas com estados de agregação da matéria diferentes (ATKINS; JONES, 2012). Buscando sempre a participação dos alunos, questionou-se: “O que diz o Princípio de Le Chatelier?”, um discente respondeu: "É aquilo que vai para esquerda". Fazendo uso dessa fala, infere-se que até então não se podia definir corretamente esse princípio fundamental no estudo do Equilíbrio Químico. Esse momento de diálogo é importante, pois segundo Cauduro et al::

\footnotetext{
O diálogo é um instrumento que permite a construção de novas relações entre as hipóteses prévias do sujeito e as ideias e os pensamentos dos demais. O resultado dessa interação é o aumento da complexidade da rede cognitiva do indivíduo. É a partir do momento em que há a partilha de experiências e a valorização do conhecimento prévio, que o sujeito passa a exercer um papel ativo, interagindo, elaborando hipóteses e criando soluções para problemas, desenvolvendo, assim, certas capacidades como questionar, refletir e argumentar (2016, p. 17).
}

Ainda nesse diálogo, explicou-se que, em geral, os sistemas tendem para um estado de equilíbrio. E o Princípio de Le Chatelier afirma que "quando uma perturbação exterior é 
aplicada a um sistema em equilíbrio dinâmico, ele tende a se ajustar para reduzir ao mínimo o efeito da perturbação" (ATKINS; JONES, 2012, p. 405).

Prosseguindo com a aplicação, questionou-se aos discentes quais fatores poderiam afetar/deslocar o equilíbrio de um(a) sistema/reação. Foi obervado que grande parte dos estudantes souberam responder. Desta forma, enfatizou-se que os fatores externos, como concentração, temperatura e pressão podem influenciar no deslocamento de uma reação (CHANG; GOLDSBY, 2013).

Após revisar como se representa uma reação química, e explicá-los que esse princípio também apresenta suas limitações, como por exemplo, no equilíbrio existente entre a formação e decomposição da amônia $\left(\mathrm{NH}_{3}\right)$ a partir dos gases hidrogênio $\left(\mathrm{H}_{2}\right)$ e nitrogênio $\left(\mathrm{N}_{2}\right)$ (ATKINS; JONES, 2012). Para explanar tal princípio, foi montado um sistema ilustrativo no

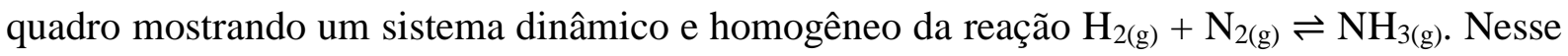
momento, foi-se discutido que o sistema consistia de um recipiente de volume inalterável (em amarelo na Figura 1) ligado a um outro recipiente (em azul também na Figura 1) contendo o gás hidrogênio $\left(\mathrm{H}_{2(\mathrm{~g})}\right)$ que seria adicionado hipoteticamente para que houvesse o suposto deslocamento da reação segundo o Princípio de Le Chatelier.

Figura 1: Ilustração do esquema em equilíbrio dinâmico da formação do $\mathrm{NH}_{3}$. (Fonte: própria)

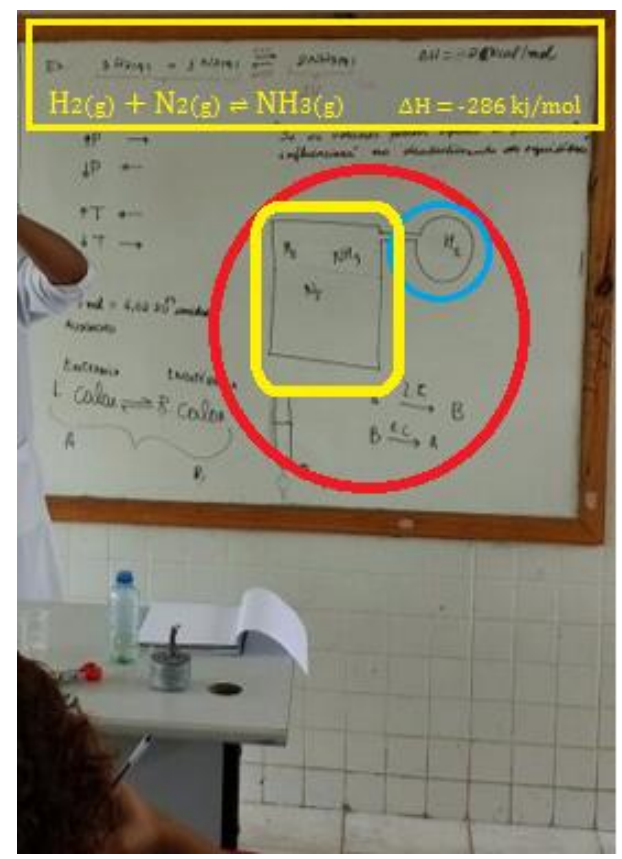

Diante disso, foi questionado aos estudantes o que aconteceria se deixássemos o hidrogênio ir para o recipiente contendo o equilíbrio. Com um pouco de incerteza, alguns discentes responderam que o equilíbrio deslocaria para o lado do produto $\left(\mathrm{NH}_{3(\mathrm{~g})}\right)$. Sob essa perspectiva, foi ressaltado que o volume do recipiente seria inalterado e a medida que fôssemos 
adicionando $\mathrm{H}_{2(\mathrm{~g})}$ a pressão no repiciente contendo o equilíbrio aumentaria, dessa forma, a pressão final seria diferente da pressão inicial. Foi explicitado que nesse caso teríamos dois fatores a serem analisados, a pressão e a concentração. No entanto, a explicação mais aprofundada dessa situação seria abordada no estudo da Termodinâmica ou por meio do quociente de reação, assuntos esses a serem trabalhados posteriormente com a turma. Foi elucidado que a afirmação deles, a de que o deslocamento do equilíbrio seria para o lado da amônia, estaria correta se fosse possível controlar a pressão do recipiente de forma que a mantivesse constante, ou seja, a pressão no recipiente antes do acréscimo de $\mathrm{H}_{2(\mathrm{~g})}$ teria que ser a mesma depois do acréscimo (CANZIAN, 2011). No entanto, essa situação hipotética aguçou os sentidos dos alunos e os alertou para que eles não se prendessem apenas a um fator e, sim, que analisassem mais amplamente o sistema. Entretanto, todos os experimentos que foram realizados em sala de aula foram explicados pelo Princípio de Le Chatelier.

Diante disso, ainda no segundo encontro, foi proposto a primeira experimentação coadunada com o conhecimento teórico abordado, sendo aquela uma forma de se contextualizar os conteúdos de Ciências (SOUZA, 2013).

Tal experimento intitulado: "Efeito do íon comum: equilíbrio de ionização da amônia" evidenciou o efeito do íon comum, através do equilíbrio de ionização da amônia. As Figuras 2 e 3, respectivamente, mostram os discentes durante essa experimentação.

Figuras 2 e 3: Discentes durante o primeiro experimento, equilíbrio de ionização da amônia. (Fonte: própria)

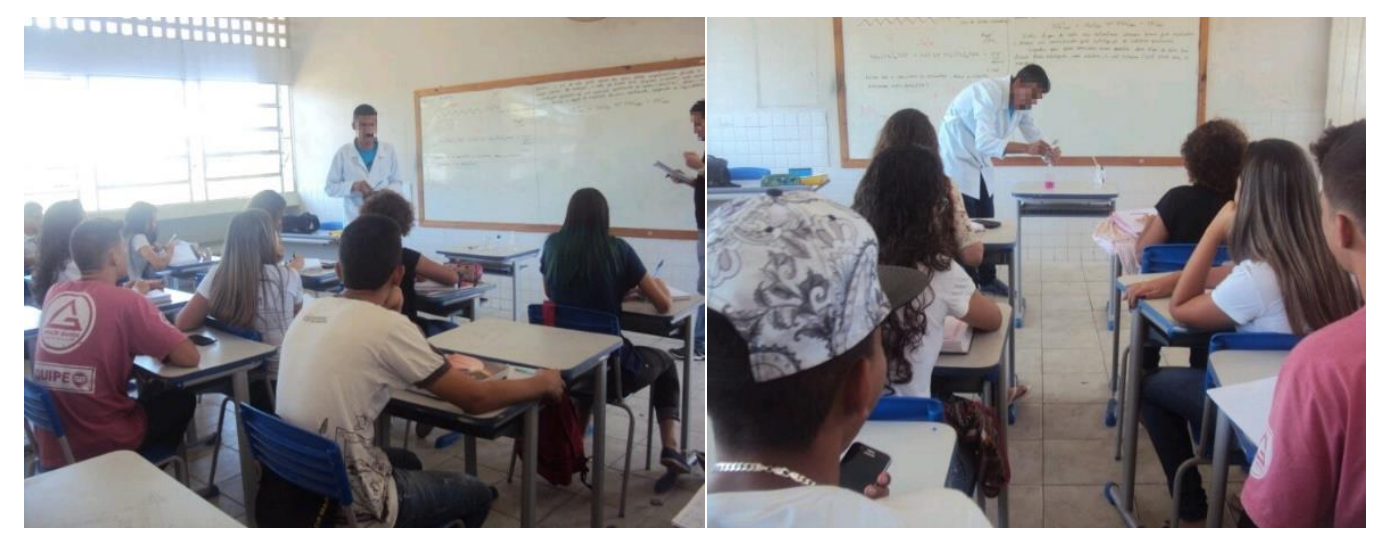

A priori, apresentou-se para a turma a solução alcoólica de fenolftaleína e perguntou-se em que tipo de situação é comum usá-la. Até então, os estudantes não tinham conhecimento dessa solução, prontamente, sucedeu-se a explicação do que seria. A solução alcoólica de fenolftaleína é uma solução incolor em meio ácido, porém, em meio básico ela se torna rosa intenso, ou seja, ela poderá nos informar a respeito da característica básica e ácida das substâncias, a solução é feita a partir de uma mistura de álcool, água e fenoltaleína (RIBEIRO 
et al., 2014).

Ao término da explanação, realizou-se o primeito experimento, adicionou-se aproximadamente $150 \mathrm{~mL}$ de água em um copo de vidro com algumas gotas de fenolftaleína. Os discentes puderam comprovar que a solução permanecia incolor, pois a água apresenta, teoricamente, um pH neutro (ATKINS, JONES, 2012). Todavia, com a adição da solução de hidróxido de amônio $\left(\mathrm{NH}_{4} \mathrm{OH}\right)$ ou solução de amônia $\left(\mathrm{NH}_{3}\right)$ (solução amoniacal), a coloração ficou rósea, indicando a basicidade do meio (CHANG; GOLDSBY, 2013). Teoricamente, o $\mathrm{NH}_{4} \mathrm{OH}$ é uma solução aquosa do gás amônia (ATKINS, JONES, 2012). Finalmente, o efeito do íon comum foi observado quando se adicionou algumas gramas de nitrato de amônio $\left(\mathrm{NH}_{4} \mathrm{NO}_{3}\right)$ e agitou-se a mistura com uma colher. A mudança de coloração indicava uma mudança no pH da reação, logo um deslocamento do equilíbrio.

Quando a amônia dissolve-se em água, ioniza-se formando os íons $\mathrm{NH}_{4}{ }^{+}$e $\mathrm{OH}^{-}$. Observou-se que a solução de hidróxido de amônio é incolor, mas com adição da fenolftaleína, essa solução torna-se rósea devido à presença dos íons $\mathrm{OH}^{-}$. Neste primeiro experimento, a adição de $\mathrm{NH}_{4} \mathrm{NO}_{3}$ à solução, acarreta um aumento na concentração de íons $\mathrm{NH}_{4}{ }^{+}$devido à dissociação do sal.

Os íons $\mathrm{NH}_{4}{ }^{+}$participam do equilíbrio de dissociação da amônia e um aumento na sua concentração provoca o deslocamento desse equilíbrio no sentido de consumir o excesso de $\mathrm{NH}_{4}{ }^{+}$adicionado (efeito do íon comum). Consequentemente, a concentração de $\mathrm{OH}^{-}$também diminui e a solução deixa de ser alcalina, o que pode ser evidenciado, pelo desaparecimento da coloração rósea.

No terceiro encontro, realizou-se o segundo experimento da pesquisa. A priori, é importante explicitar, como foi montado tal experimento. Para tanto, foi montado um sistema com garrafa PET (Figura 4), em que utilizou-se uma mangueira de látex que serviu para transpassar um furo feito na tampa da garrafa, de forma que não possibilitasse folga, evitando assim, que escapasse algum tipo de matéria, a não ser pelo tubo da mangueira.

Figura 4: Montagem do sistema utilizado no segundo experimento. (Fonte: própria)

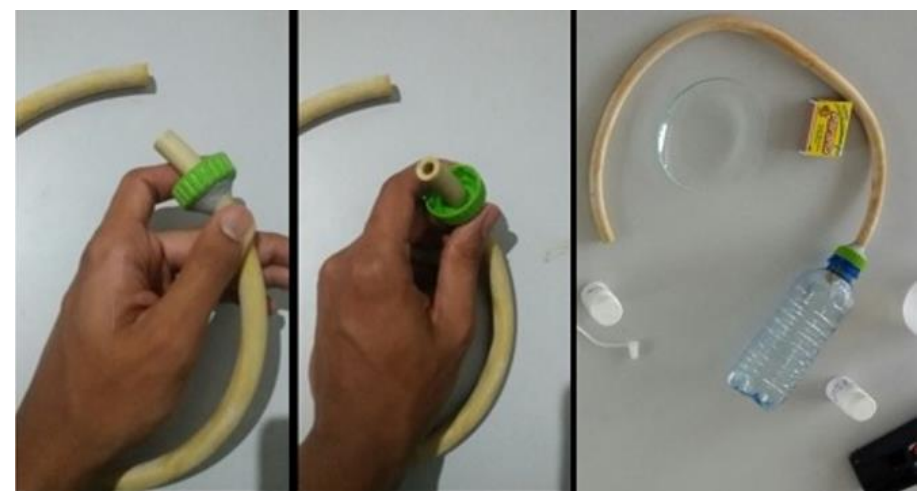

[103] 
Dando continuidade, foram apresentadas as substâncias, entre elas, a fenolftaleína (vista já anteriormente por eles), o vinagre e o sal, bicarbonato de sódio. Nesse momento, indagou-se ao estudantes se eles já tinham ouvido falar nesse sal e qual seria a sua fórmula. Os alunos declararam que já tinham ouvido falar, e que servia para uso de processo caseiro de clareamento dentário, mas que não sabiam qual a fórmula.

Foi explicado para eles que o bicarbonado de sódio é o nome comercial para o composto hidrogeno-carbonato de sódio, ou, carbonato ácido de sódio. O bicarbonato de sódio faz parte da função inorgânica classificada como hidrogeno-sal ou sal ácido. Os sais ácidos apresentam dois cátions, e um ânion. No caso do bicarbonato de sódio, encontra-se em sua fórmula: $\mathrm{NaHCO}_{3}$, o cátion sódio $\left(\mathrm{Na}^{+}\right)$e o cátion hidrogênio $\left(\mathrm{H}^{+}\right)$, dois cátions, e o íon carbonato $\left(\mathrm{CO}_{3}{ }^{-}\right.$ ${ }^{2}$ ) como o ânion (ATKINS; JONES, 2012). Além disso, o bicarbonato de sódio é comumente utilizado como: Desodorantes, extintor de incêndio, fermento para massa de bolo, antiácido estomacal - reagindo com o ácido clorídrico para formar cloreto de sódio, água e gás carbônico (ATKINS; JONES, 2012).

E, por último, foi questionado à turma se conhecia o principal componente do vinagre. Em resposta, alguns discentes responderam que é um ácido, mas não sabiam qual ácido. Diante disso, foi esclarecido que o componente mais importante do vinagre é o ácido acético, nome dado ao ácido etanóico que tem fórmula $\mathrm{CH}_{3} \mathrm{COOH}$ (SOLOMONS, 2009).

Após a explanação das substâncias que seriam utilizadas, o segundo experimento: "Efeito da concentração: equilíbrio de hidrólise do íon bicarbonato", foi executado. Foi adicionada uma pitada de bicarbonato de sódio em aproximadamente $100 \mathrm{~mL}$ de água contida em um erlenmeyer. Em seguida, adicionou-se algumas gotas da solução alcoólica de fenolftaleína, com isso, foi observada a mudança de cor (rósea), como mostrada na Figura 5 (da esquerda). Quando visto a mudança de cor, os estudantes, afirmaram, antes mesmos de serem questionados, que a solução era básica. Em seguida, colocou-se cerca de $100 \mathrm{~mL}$ de vinagre na garrafa PET, e estando preparado para fechar a garrafa com a tampa-mangueira, adicionou-se uma colher de sopa de bicarbonato de sódio ao vinagre; fechou-se a garrafa, mantendo a outra extremidade dentro da solução de bicarbonato de sódio no erlenmeyer e outra no béquer como ilustra a Figura 6 (da direita): 
Figuras 5 e 6: Aplicação do experimento sobre efeito da concentração no equilíbrio. (Fonte: própria)

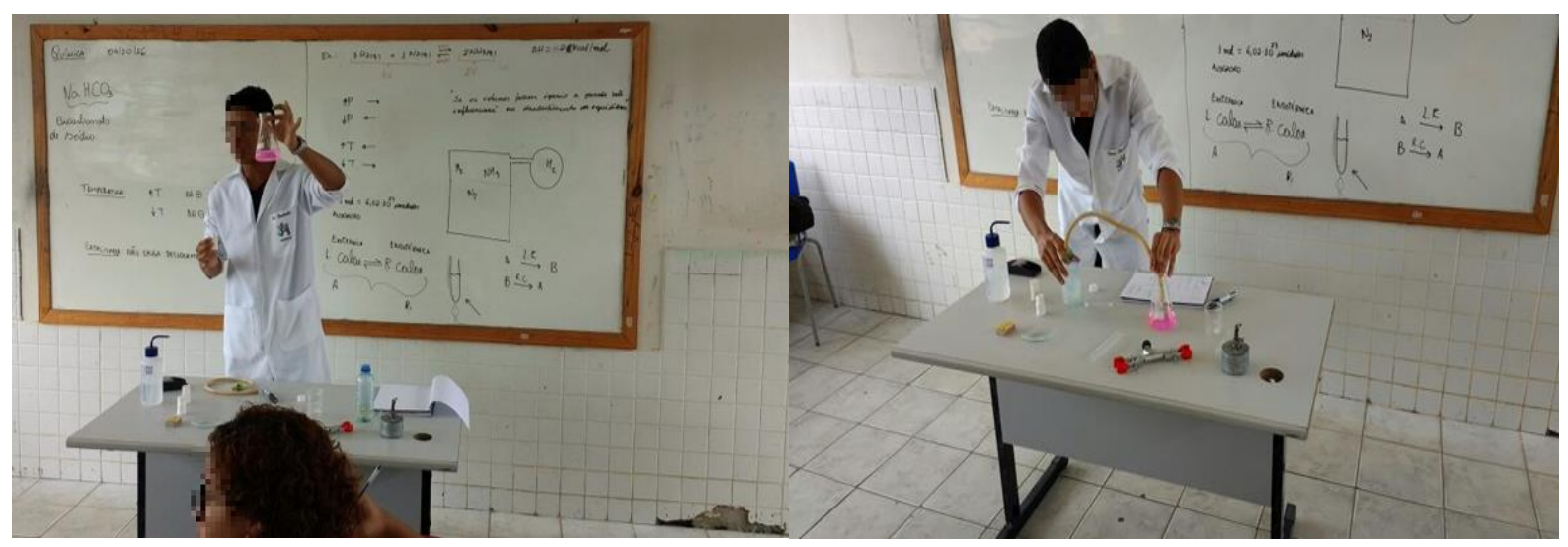

Quando adicionado o bicarbonato de sódio ao vinagre, foi observado uma efervercência e liberação do gás $\mathrm{CO}_{2}$ que estava sendo guiado pela mangueira de latex ao erlenmeyer. Depois de algum tempo, a solução começou a ter sua coloração restaurada, tornando-se incolor. Após o clareamento da solução de bicarbonato, foi indagado aos alunos o que poderia ter acontecido. De início, eles afirmaram que "a solução deixou de ser básica para ser ácida”. Depois, alguns disseram que "houve deslocamento no equilíbrio", mas não sabiam como isso se deu.

Em seguida, por meio da discussão, foi explicado o que aconteceu. A explicação se dividiu em três etapas. A primeira etapa foi explicar o que aconteceu dentro do erlenmeyer (antes do acréscimo de gás carbônico).

Quando adicionou-se o bicarbonato de sódio a água, houve a dissociação do $\mathrm{NaHCO}_{3}$ nos íons $\mathrm{Na}^{+}$e $\mathrm{HCO}_{3}{ }^{-}$, conforme mostra a Equação 1 (SKOOG et al., 2006):

$$
\mathrm{NaHCO}_{3(\mathrm{~s})} \stackrel{\text { Água }}{\longrightarrow} \mathrm{Na}^{+}{ }_{(\mathrm{aq})}+\mathrm{HCO}_{3}{ }_{(\mathrm{aq})} \text { (Equação 1) }
$$

Como produto dessa hidrólise, tem-se o íon sódio $\left(\mathrm{Na}^{+}\right)$e o íon bicarbonato $\left(\mathrm{HCO}_{3}{ }^{-}\right) . \mathrm{O}$ íon bicarbonato, no entanto, também reagiu com a água para formar ácido carbônico $\left(\mathrm{H}_{2} \mathrm{CO}_{3(\mathrm{aq})}\right)$ e o íon hidróxido $\left(\mathrm{OH}^{-}\right)$(Equação 2):

$$
\mathrm{HCO}_{3}^{-}{ }_{(\mathrm{aq})}+\mathrm{H}_{2} \mathrm{O}_{(\mathrm{l})} \rightleftharpoons \mathrm{H}_{2} \mathrm{CO}_{3(\mathrm{aq})}+\mathrm{OH}_{(\mathrm{aq})}^{-} \quad(\text { Equação 2) }
$$

A presença do íon $\mathrm{OH}^{-}$permitiu a mudança de coloração para rósea. Na segunda etapa, foi explicado o que aconteceu na garrafa ao adicionar o bicarbonato de sódio ao vinagre, respectivamente, de acordo com a Equação 3:

$$
\mathrm{NaHCO}_{3(\mathrm{aq})}+\mathrm{H}_{3} \mathrm{CCOOH}_{(\mathrm{aq})} \rightarrow \mathrm{H}_{3} \mathrm{CCOONa}_{(\mathrm{aq})}+\mathrm{H}_{2} \mathrm{CO}_{3(\mathrm{aq})} \quad \text { (Equação 3) }
$$

Conforme essa equação, foram formados o acetato de sódio $\left(\mathrm{H}_{3} \mathrm{CCOONa}\right)$ e o ácido carbônico. Como o ácido carbônico é instável, logo há formação do gás carbônico, que foi o responsável pela efervescência, e água (Equação 4).

$$
\underline{\mathrm{H}}_{2} \underline{\mathrm{CO}}_{3(\mathrm{aq})} \rightleftharpoons \underline{\mathrm{CO}}_{2(\mathrm{~g})} \uparrow+\underline{\mathrm{H}}_{2} \underline{\mathrm{O}}_{(\mathrm{l})} \quad \text { (Equação 4) }
$$


Na terceira etapa, foi explanada a reação que ocorreu dentro do erlenmeyer depois que o gás carbônico entrou em contato com a solução de bicarbonato de sódio. Por se tratar de uma solução aquosa, moléculas de águas existentes no meio começaram a reagir com esse gás. Isso gerou a formação de mais ácido carbônico na solução. $\mathrm{O}$ aumento da concentração de $\mathrm{H}_{2} \mathrm{CO}_{3}$ fez com que o equilíbrio de hidrólise (Equação 2) fosse deslocado para o sentido do reagente, assim esperado, pelo princípio de Le Chatelier que afirma que: "Se adicionarmos uma nova quantidade de um dos componentes a um sistema em equilíbrio, ocorrerá reação para consumir parte da adicionada. De modo reverso, a remoção de parte de um componente favorece a ocorrência de reação para substituí-lo” (CONSTANTINO, SILVA, DONATE, 2004, p. 243). Como consequência, os íons $\mathrm{OH}^{-}$foram consumidos, resultando no desaparecimento da cor roséa.

Na sequência, foi aplicado o terceiro experimento: Efeito da temperatura no equilíbrio de ionização da amônia, realizado no quarto encontro, o qual consistiu em demonstrar o efeito da temperatura no equilíbrio das reações. Em um tubo de ensaio, colocou-se cerca de $5 \mathrm{~mL}$ de hidróxido de amônio $\left(\mathrm{NH}_{4} \mathrm{OH}\right)$ em $100 \mathrm{~mL}$ de água, porém, utilizou-se para o experimento apenas uma pequena quantidade dessa solução, colocando-a em outro tubo de ensaio. A este foram adicionadas algumas gotas de fenolftaleína, o qual verificou-se a cor roséa, indicando uma solução básica. Em seguida, aqueceu-se o tubo e foi notado o desaparecimento dessa cor. Foi explicado para os alunos que a reação de ionização da amônia é um processo exotérmicoe e que se dá pela Equação 5:

$$
\mathrm{NH}_{3}(\mathrm{aq})+\mathrm{H}_{2} \mathrm{O}_{(\mathrm{l})} \rightleftharpoons \underbrace{\mathrm{NH}_{4}{ }_{(\mathrm{aq})}+\mathrm{OH}^{-}{ }_{(\mathrm{aq})}}_{\mathrm{NH}_{4} \mathrm{OH}}(\Delta \mathrm{H}<0) \quad(\text { Equação 5) }
$$

Para um melhor entendimento, foi indagado aos estudantes se eles conheciam o significado da expressão $(\Delta \mathrm{H}<0)$. Os discentes responderam que sim, dizendo que indicava uma reação com liberação de calor, e quando a expressão fosse inversa, isto é, $(\Delta H>0)$, significava que a reação absorvia calor. Todavia, foi observado que alguns confundiam quando se falava em exotérmica e endotérmica. A fim de consolidar os conceitos, foi dito que, as reações que apresentam $\Delta \mathrm{H}<0$ são exotérmicas, ou seja, liberam calor, e aquelas com $\Delta \mathrm{H}>0$ são endotérmicas, portanto, absorvem calor (ATKINS; JONES, 2012).

Desta forma, foi possível esclarecer que, o aquecimento fez com que o equilíbrio se deslocasse para o sentido dos reagentes, o que levou o desaparecimento do íon hidróxido, ocasionando a ausência da cor rósea. Com isso, os discentes puderam comprovar o que o 
princípio de Le Chatelier afirma a respeito da temperatura como fator para o deslocamento da reação:

O princípio de Le Chatelier está de acordo com essas observações. Podemos imaginar que o aquecimento gerado na reação exotérmica ajuda a compensar o abaixamento da temperatura. Do mesmo modo, podemos imaginar que o calor absorvido em uma reação endotérmica ajuda a compensar o aumento da temperatura. Em outras palavras, o aumento da temperatura de uma mistura de reação desloca o equilíbrio na direção endotérmica. (ATKINS; JONES, 2012, p. 410)

Ao final da aplicação, ainda nesse quarto encontro, por intermédio de um Questionário Final, perguntou-se aos discentes quais conteúdos pareceram-lhes os mais fáceis ou de melhor assimilação e quais os mais difíceis ou de menor assimilação. Ao responderem, verificou-se que houve uma mudança de pensamento em relação ao conteúdo: "Princípio de Le Chatelier". Um estudante escreveu: "Entendi esse princípio, a gente (observa) quando tem perturbação na nossa reação, tudo ocorre para que volte ao equilíbrio do começo. A gente viu nos experimentos do professor. Seria bom sempre aulas assim." Neste trecho foi observado que as competências e habilidades foram aprendidas. Sendo assim, infere-se que, por meio do debate, da experimentação, do diálogo e da reflexão, os discentes obtiveram êxito em assimilar os conteúdos trabalhados.

\section{CONSIDERAÇÕES FINAIS}

Esse estudo buscou auxiliar o método tradicional (quadro e giz) de ensino utilizando-se de instrumentos metodológicos que pudessem atribuir uma abordagem Química desmitificada, a qual pudesse respeitar a autonomia de cada discente em sala de aula, bem como utilizar de suas opiniões e vivências, para exemplificar e denotar esta ciência presente no nosso dia a dia.

No estudo de Equilíbrio, o Princípio de Le Chatelier é um dos conceitos mais simples e fundamentais, todavia, compreender o seu real significado requer conhecer o problema que lhe deu origem e o encaminhamento correto para resolução. Caso contrário, os discentes podem apenas memorizar mecanicamente uma definição, sem vinculá-la ao seu cotidiano. Sendo assim, o uso de ferramentas didáticas, como a experimentação e da abordagem de CiênciaTecnologia-Sociedade mostrou que houve um impacto positivo no aprendizado dos discentes, demonstrando quais conteúdos tiveram uma melhor assimilação. De forma geral, os estudantes compreenderam bem o conteúdo e mostraram-se entusiasmados com a abordagem do trabalho. É importante ressaltar que durante todo momento da investigação, foi levado em consideração o conhecimento prévio de cada discente, pois só assim, conseguiu-se dar significância ao conteúdo estudado. 


\section{REFERÊNCIAS}

AGÊNCIA BRASIL. Governo envia MP com reforma do ensino médio e propõe ampliar educação integral. Disponível em <http://agenciabrasil.ebc.com.br/educacao/noticia/201609/governo-envia-mp-com-reforma-do-ensino-medio-e-propoe-ampliar-educacao > Acesso em: 08 de nov. 2017.

ATKINS, P.; JONES, L.; Princípios de química: questionando a vida moderna e o meio ambiente. 5. ed. Tradução: Ricardo Bicca de Alencastro. São Paulo: Bookman, 2012.

BARBOSA, D. et al. Desafios para a docência em química: teoria e prática.São Paulo: Universidade Estadual Paulista: Núcleo de Educação a Distância, 2013. Disponível em: $<$ https://acervodigital.unesp.br/bitstream/unesp/155336/1/unesp-nead-redefor2ed-ebook_tcc_quimica.pdf.> Acesso em: 08 de nov. 2017.

BELLONI, M. O que é mídia-educação. Campinas: Autores Associados, 2005.

BRASIL. Lei de Diretrizes e Bases da Educação Nacional, LDB nº 9.394, de 20 de dezembro de 1996.

Ministério da Educação - Secretaria de Educação Média e Tecnológica. Parâmetros Curriculares Nacionais: Ensino Médio: Ciências da Natureza, Matemática e suas Tecnologias. Brasília: MEC/SEMTEC, 1999.

. Ministério da Educação - Secretaria de Educação Média e Tecnológica. Parâmetros Curriculares Nacionais: Ensino Médio: Ciências da Natureza, Matemática e suas Tecnologias. Brasília: MEC/SEMTEC, 2002.-

Ministério da Educação - Secretária de Educação Profissional e Tecnológica. Funcionários de escolas: cidadãos, educadores, profissionais e gestores / João Antonio Cabral de Molevade, - $4^{\text {a }}$ ed. atualizada e revisada - Cuiabá: Universidade Federal de Mato Grosso, Rede e-Tec Brasil, 2012.

Ministério da Educação - Fundo Nacional de Desenvolvimento da Educação. Guia PNLD 2017. Disponível em: <http://www.fnde.gov.br/programas/programas-do-livro/livrodidatico/guia-do-livro-didatico/item/8813-guia-pnld-2017> Acesso em: 08 de nov. 2017.

CALEFFE, L. G.; MOREIRA, H. M. Metodologia da pesquisa para o professor pesquisador. $2^{\circ}$ Ed. Rio de Janeiro: Lamparina, 2008.

CANZIAN, R. Análise do princípio de Le Chatelier em livros didáticos de química. São Paulo, 2011. 81f. Dissertação (Ensino de Química). Faculdade de Educação, Universidade de São Paulo, 2011.

CATARINA, I. Interdisciplinaridade: História, Teoria e Pesquisa. $15^{\circ}$ Edição. São Paulo: Papirus. 2008

CAUDURO, A., et al. Envelhecimento e Suas Múltiplas Áreas do Conhecimento. Porto Alegre: Edipucrs, 2016. 
CHANG, R.; GOLDSBY, K. A. Química. 11ª ed. Porto Alegre: AMGH, 2013.

COnstantino, M. G.; SIlva, G. V.; DOnATE, P. M. Fundamentos de Química Experimental. São Paulo: EdUSP, 2004.

FREIRE, P. Pedagogia da Autonomia: saberes necessários à prática educativa. $48^{\mathrm{a}} \mathrm{ed}$. Rio de Janeiro: Editora Paz e Terra, 2014.

HOFSTEIN, A. The laboratory in Science education: foundations for the twenty-first century. Science Education, v. 88, n. 1, p. 1-8, 1998.

INSTITUTO NACIONAL DE ESTUDOS E PESQUISAS EDUCACIONAIS ANÍSIO TEIXEIRA - INEP. Sinopses Estatísticas da Educação Básica. Disponínel em: <http://portal.inep.gov.br/basica-censo-escolar-sinopse-sinopse> Acesso em: 08 de nov. 2017.

MARCONI, M. A.; LAKATOS, E. M. Metodologia científica. 6 ed. São Paulo: Atlas, 2011.

NARDI, Roberto. Questões atuais no ensino de ciências. São Paulo: Escrituras, 1998.

PIAGET, J. A formação do símbolo na criança. Rio de Janeiro: Zahar, 1975.

RIBEIRO, D. et al. Corrosão e, estruturas de concreto armado: Teoria, controle e métodos de análise. Rio de Janeiro: Campus Elsevier Brasil, 2014.

SEVERINO, A. J. Metodologia do trabalho científico. 23ª edição. São Paulo: Cortez, 2008.

SKOOG et al. Fundamentos de Química Analítica, Tradução da $8^{a}$ Edição norte-americana, São Paulo: Editora Thomson, 2006.

SOLOMONS, G. T. Química Orgânica, 10ª ed., Vol. 1, São Paulo: Editora LTC, 2009.

SOUZA, J. J. N. Experimentação no ensino noturno: uma proposta para o ensino de Química. Brasília. 2013, 120f. Tese de doutorado (Ensino de Ciências). Faculdade de Educação, Universidade de Brasília, 2013.

SOUZA, V. C. A., JUSTI, R. S. O Ensino de Ciências e seus Desafios Humanos e Científicos: fronteiras entre o saber e o fazer científico. In: V Encontro Nacional de Pesquisa em Educação em Ciências, 2005, Anais do Encontro Nacional de Pesquisa em Educação em Ciências, Bauru: UFRJ, 2005. Disponível em <http://www.nutes.ufrj.br/abrapec/vienpec/CR2/p40.pdf>. Acesso em: 10 nov. 2017. 